\title{
The Extreme Precipitation Index (EPI): A Coupled Dynamic-Thermodynamic Metric to Diagnose Midlatitude Floods Associated with Flow Reversal
}

\author{
SHAWN M. MiLRAD \\ Meteorology Program, Applied Aviation Sciences Department, Embry-Riddle Aeronautical University, Daytona Beach, Florida \\ Eyad H. ATALlah AND JOHN R. GyAKUM \\ Department of Atmospheric and Oceanic Sciences, McGill University, Montreal, Quebec, Canada \\ RACHAEL N. ISPHORDING \\ Oak Ridge National Laboratory, Oak Ridge, Tennessee \\ JONATHON KLEPATZKI \\ Meteorology Program, Applied Aviation Sciences Department, Embry-Riddle Aeronautical University, Daytona Beach, Florida
}

(Manuscript received 12 September 2018, in final form 4 July 2019)

\begin{abstract}
The extreme precipitation index (EPI) is a coupled dynamic-thermodynamic metric that can diagnose extreme precipitation events associated with flow reversal in the mid- to upper troposphere (e.g., Rex and omega blocks, cutoff cyclones, Rossby wave breaks). Recent billion dollar (U.S. dollars) floods across the Northern Hemisphere midlatitudes were associated with flow reversal, as long-duration ascent (dynamics) occurred in the presence of anomalously warm and moist air (thermodynamics). The EPI can detect this potent combination of ingredients and offers advantages over model precipitation forecasts because it relies on mass fields instead of parameterizations. The EPI's dynamics component incorporates modified versions of two accepted blocking criteria, designed to detect flow reversal during the relatively short duration of extreme precipitation events. The thermodynamic component utilizes standardized anomalies of equivalent potential temperature. Proof-of-concept is demonstrated using four high-impact floods: the 2013 Alberta Flood, Canada's second costliest natural disaster on record; the 2016 western Europe Flood, which caused the worst flooding in France in a century; the 2000 southern Alpine event responsible for major flooding in Switzerland; and the catastrophic August 2016 Louisiana Flood. EPI frequency maxima are located across the North Atlantic and North Pacific mid- and high latitudes, including near the climatological subtropical jet stream, while secondary maxima are located near the Rockies and Alps. EPI accuracy is briefly assessed using pattern correlation and qualitative associations with an extreme precipitation event climatology. Results show that the EPI may provide potential benefits to flood forecasters, particularly in the 3-10-day range.
\end{abstract}

\section{Introduction}

Extreme precipitation events are typically caused by a combination of large rainfall rates and long rainfall duration (e.g., Doswell et al. 1996; Gyakum 2008). In a study of Southeast U.S. extreme precipitation, Moore et al. (2015) found two event types: 1) high-amplitude flow patterns associated with strong poleward water vapor transport and conditionally unstable moist air, and 2) relatively low-amplitude flow patterns with weaker water vapor transport but a more conditionally unstable

Corresponding author: Shawn M. Milrad,milrads@erau.edu and moist air mass. The extreme precipitation index (EPI) developed in this study can detect a subset of extreme precipitation events associated with midlatitude flow reversal. Patterns related to flow reversal include but are not limited to the following: cyclonic wave breaks (CWB) and anticyclonic Rossby wave breaks (AWB; e.g., Martius et al. 2007; Bowley et al. 2019), Rex blocks (Rex 1950), omega blocks, and closed/cutoff mid- to upper-tropospheric cyclones (e.g., Bell and Bosart 1989;

Publisher's Note: This article was revised on 23 September 2020 to include Rachael N. Isphording as a coauthor instead of acknowledging her in the Acknowledgments section, as originally published. 
Abatzoglou 2016). To do this, the EPI combines flow reversal (dynamics) with a measure of anomalous heat and moisture (thermodynamics). Reversed flow patterns can increase precipitation amounts and flooding risks through increased rainfall duration due to the slow propagation of features such as closed/cutoff mid- to upper-tropospheric cyclones. CWB and AWB are also related as they can but do not always result in reversed flow features.

Numerous recent Northern Hemisphere (NH) midlatitude floods associated with flow reversal have resulted in billions of dollars [U.S. dollars (USD)] in losses. Examples include the summer 2010 Pakistan Flood (Lau and Kim 2012; Martius et al. 2013; Yamada et al. 2016), June 2013 Alberta Flood (Milrad et al. 2015, 2017; Teufel et al. 2017), September 2013 Great Colorado Flood (Lavers and Villarini 2013; Gochis et al. 2015), May-June 2016 France/Germany/Belgium (hereafter western Europe) Flood (Philip et al. 2018), August 2016 Louisiana Flood (Wang et al. 2016), and several floods in the Alps this century (Stucki et al. 2012; Grams et al. 2014; Piaget et al. 2015; Barton et al. 2016; Lenggenhager et al. 2019).

In June 2013, the Alberta Flood (Milrad et al. 2015; Teufel et al. 2017) featured $>130 \mathrm{~mm}$ of rainfall in the southern Alberta foothills, resulting in the secondcostliest natural disaster in Canadian history ( $\sim 2$ billion USD insured losses). The late May-early June 2016 western Europe Flood (Philip et al. 2018) caused the worst flooding in Paris in nearly a century, while the October 2000 southern Alpine Flood caused extensive damage near Lago Maggoire in Switzerland. In August 2016, the Louisiana Flood (Wang et al. 2016) caused evacuations of 20000 people and resulted in more than three times as much rainfall as Hurricane Katrina in parts of Louisiana, particularly near Baton Rouge.

Figure 1 shows European Centre for MediumRange Weather Forecasts (ECMWF) interim reanalysis (ERA-Interim, hereafter ERA-I; Dee et al. 2011) plots at 0000 UTC on the day of heaviest precipitation for each of the four floods. The Alberta Flood (Figs. 1a,b) was marked by a closed mid- to uppertropospheric cyclone over the northwestern United States. This cyclone combined with an amplifying midto upper-tropospheric ridge north of the flood region to form a Rex block (Rex 1950) in the presence of anomalously warm and moist air over the flood region (Milrad et al. 2015; 2017). The 2016 western Europe Flood (Figs. 1c,d) was associated with a closed midtropospheric cyclone over central France. Meanwhile, anomalously warm and moist air was transported northward into western Germany, Belgium, and northern France, contributing to a long-duration extreme precipitation event (Philip et al. 2018). The 2000 southern Alpine Flood (Lenggenhager et al. 2019) was associated with an omega block pattern over much of Europe (Figs. 1e,f). Finally, the 2016 Louisiana Flood was associated with a weak lower- to midtropospheric cyclonic disturbance (Wang et al. 2016) located over the northern Gulf of Mexico, in association with very anomalous warm and moist air (Figs. 1g,h).

For extreme precipitation events, the importance of surface cyclones (Pfahl and Wernli 2012) and uppertropospheric cutoff cyclones (Abatzoglou 2016) has been previously quantified for the globe and United States, respectively. In addition, a few case studies of floods associated with flow reversal have been examined (e.g., Gochis et al. 2015; Milrad et al. 2015; Philip et al. 2018; Lenggenhager et al. 2019). However, no study to our knowledge has systematically developed and evaluated a diagnostic metric that can capture the dynamic and thermodynamic ingredients of midlatitude extreme precipitation events associated with flow reversal.

Definitions of extreme precipitation vary in the literature. For example, Groisman et al. (2012) examined trends in events $\geq 6$ in. $(\sim 150 \mathrm{~mm})$, while Sukovich et al. (2014) at the NOAA Weather Prediction Center (WPC) analyzed the skill of human quantitative precipitation forecasts (QPF) for events of 1 and $3 \mathrm{in}$. (25.4 and $76.2 \mathrm{~mm}$, respectively), which are key thresholds for WPC operational forecasts. The EPI is generally designed with the WPC (e.g., Sukovich et al. 2014) extreme precipitation event thresholds in mind.

QPF remains an important challenge, especially during extreme events (Sisson and Gyakum 2004). While the forecast accuracy of mass fields (e.g., geopotential height, wind, temperature) has greatly improved, QPF skill lags. Sukovich et al. (2014) showed that for daily precipitation events $\geq 1$ in. $(25.4 \mathrm{~mm})$, human-produced QPF at the WPC, which is ostensibly influenced by mass field forecasts, exceeded model QPF skill by $30 \%-40 \%$. This is particularly true in the warm season, when convective precipitation is often a large component of QPF (Fritsch and Carbone 2004). The EPI may prove particularly useful in probabilistic human forecast products to help identify the likelihood and potential location of midlatitude extreme precipitation events associated with flow reversal.

The remainder of this study is organized as follows: section 2 details data used and develops the EPI, section 3 provides proof-of-concept case studies for the four aforementioned high-impact floods, and section 4 examines NH flow reversal and EPI frequency climatologies. Finally, a brief EPI accuracy evaluation is detailed in section 5 and the conclusions are presented in section 6 .

\section{Data and EPI formulation}

\section{a. Data}

We calculated and evaluated the EPI using the ERA-I reanalysis (Dee et al. 2011), which has a 
500-hPa
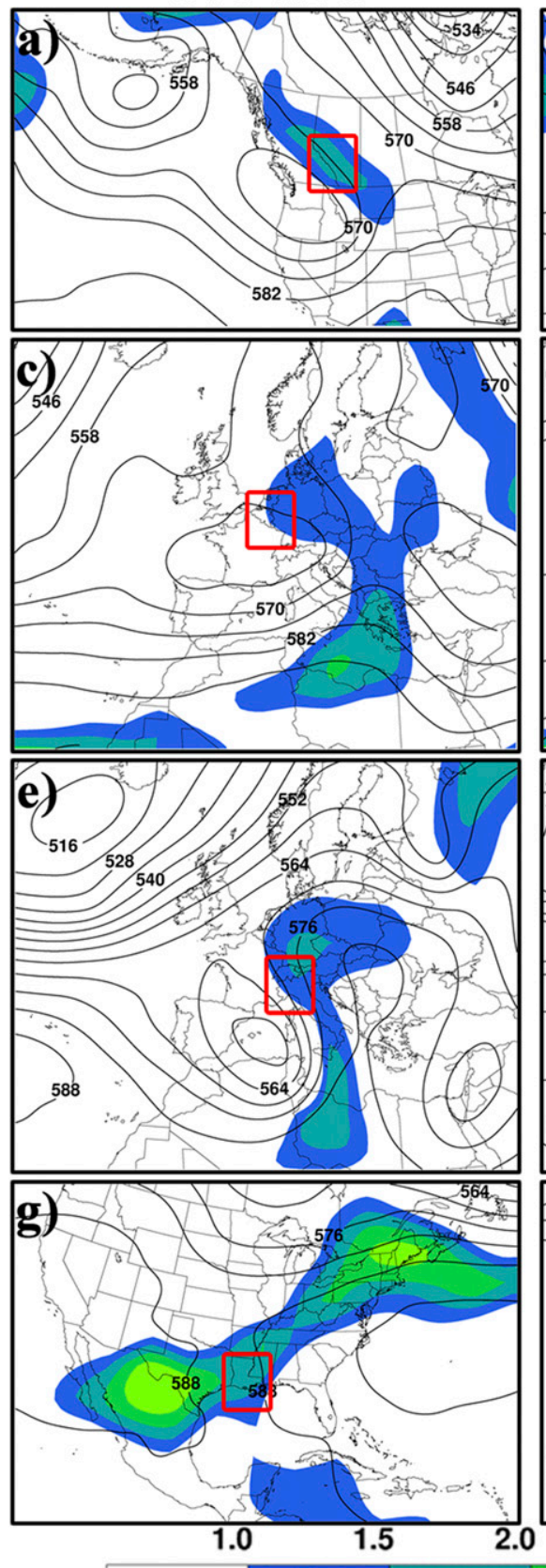

DT
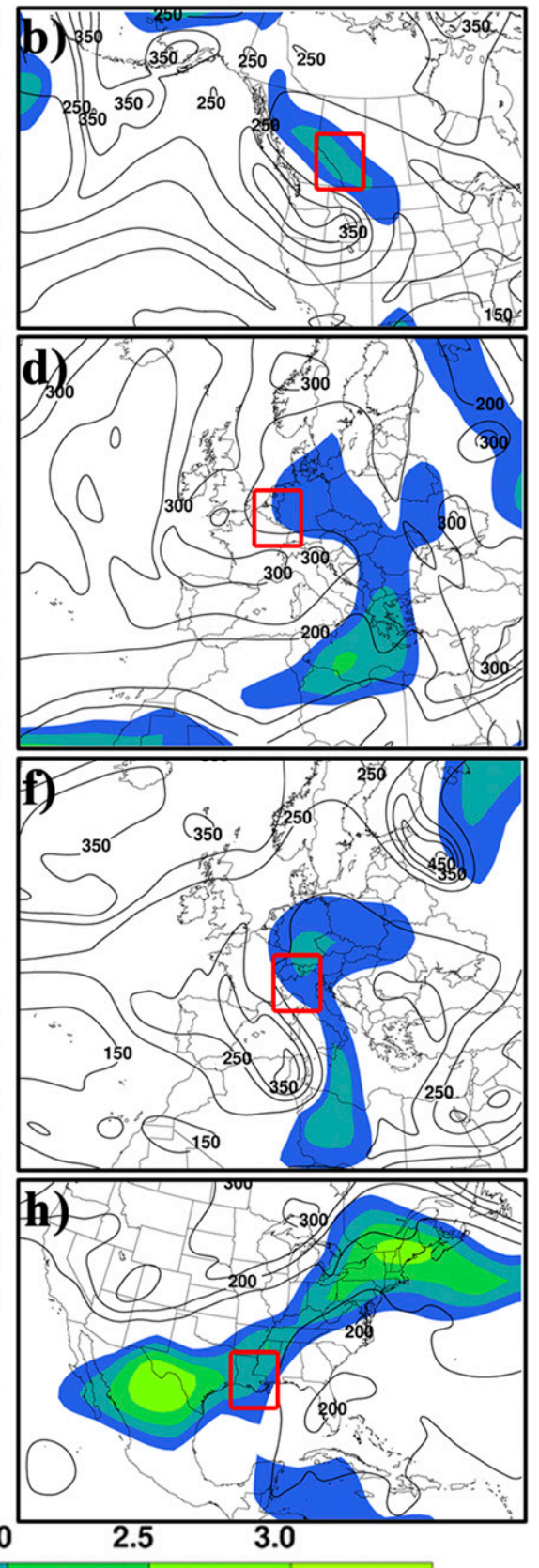

FIG. 1. ERA-Interim (left) 500-hPa geopotential height (dam; solid black contours) and (right) DT pressure (hPa; solid black contours), with standardized anomalies of $700-400-\mathrm{hPa}$ layer-averaged equivalent potential temperature $\left[\sigma_{\theta_{e}}\right.$ in Eq. (1); shaded] on all panels for: (a),(b) 0000 UTC 20 Jun 2013 (Alberta Flood), (c),(d) 0000 UTC 30 May 2016 (western Europe Flood), (e),(f) 0000 UTC 15 Oct 2000 (southern Alpine Flood), and (g),(h) 0000 UTC 14 Aug 2016 (Louisiana Flood). The red boxes outline the regions of heaviest precipitation in each case.

spectral T255 horizonal resolution corresponding to a $\sim 79-\mathrm{km}$ grid spacing, temporal resolution of $6 \mathrm{~h}$, 60 vertical levels, and is available from 1979 to the present. Results were compared to the coarser $\left(2.5^{\circ}\right.$ grid spacing) National Centers for Environmental Prediction-National Center for Atmospheric Research (NCEP-NCAR) global reanalysis (Kalnay et al. 1996) and found to be similar. 
For our case studies (section 3) and accuracy evaluation (section 5), we primarily used ERA-I daily precipitation. Because ERA-I precipitation is model derived, we verified it with daily data from the Global Precipitation Climatology Centre (GPCC) (Schamm et al. 2015), which has a relatively similar $1^{\circ}$ horizontal grid spacing. The GPCC is a reliable global gridded precipitation dataset based on rain gauge data. However, to fully evaluate the EPI, we needed to compare it to a gridded dataset that includes precipitation over water (i.e., ERA-I), which the GPCC does not. Although Lenggenhager et al. (2019) stated that the ERA-I does sometimes slightly underestimate precipitation in extreme events, we found ERA-I precipitation to be qualitatively reliable if not always quantitatively accurate.

Graphics throughout the manuscript were created using the General Meteorological Package (GEMPAK), version 7.4.1, updated from the original package of Koch et al. (1983). The correlation diagnostics presented in section 5 were calculated using the NCAR Command Language, version 6.5.0 (NCAR 2018).

\section{b. EPI formulation}

We devised two EPI versions, each incorporating modified versions of operationally accepted blocking criteria. The first, 500-hPa EPI, is based on the geopotential height criterion devised by Lejenas and Okland (1983) and refined by Tibaldi and Molteni (1990). The second, dynamic tropopause [DT, defined here as the 2-PVU surface; $1 \mathrm{PVU}=10^{-6} \mathrm{~K} \mathrm{~kg}^{-1} \mathrm{~m}^{2} \mathrm{~s}^{-1}$ ] EPI, is based on the DT blocking criterion of Pelly and Hoskins (2003). The EPI formulation is shown by Eq. (1):

$$
\mathrm{EPI}=\mathrm{FR} \times \sigma_{\theta_{e}} \int_{700}^{400} \frac{\partial r_{s}}{\partial p} \times 1000,
$$

where FR is the respective flow reversal criterion, $\sigma_{\theta_{e}}$ is the standardized anomaly of $700-400-\mathrm{hPa}$ layeraveraged equivalent potential temperature $\theta_{e}$, and $\partial r_{s} / \partial p$ is the integrated layer-averaged $(700-400 \mathrm{hPa})$ vertical change in saturation mixing ratio. Finally, a scaling factor of 1000 is included such that saturation mixing ratio becomes unitless $\left(\mathrm{kg} \mathrm{kg}^{-1}\right)$.

Standardized anomalies were calculated using daily deviations from a 1981-2010 ERA-I climatology. Using standardized anomalies of $\theta_{e}$ allows the EPI to function independently of season. We chose $700-400 \mathrm{hPa}$ because it is generally located above all terrain influences and is the layer most commonly associated with precipitation production. We evaluated the EPI using column precipitable water instead of 700-400-hPa layer-averaged $\theta_{e}$ and found that our case studies and climatologies were less robust and precise. The integrated vertical change in saturation mixing ratio was incorporated to eliminate spurious EPI maxima in polar regions, which were an issue in early testing. Specifically, polar regions can feature large standardized anomalies of $\theta_{e}$ in situations where overall heat and moisture content is still too small to produce an extreme precipitation event; incorporating $\partial r_{s} / \partial p$ largely eliminated this problem.

Both versions of the EPI are unitless quantities, as all variables in Eq. (1) are or become unitless with scaling. FR is a binary variable based on the modified criteria specified in Table 1 . If the respective criteria are met at a gridpoint, then FR is assigned a value of 1 at that gridpoint. If the criteria in Table 1 are not met, then FR is assigned a value of 0 . Therefore, the EPI will always equal zero if flow reversal is not detected.

To calculate FR in Eq. (1), we reduced the temporal and spatial scale criteria from the original blocking definitions of Tibaldi and Molteni (1990) and Pelly and Hoskins (2003), respectively (Table 1). These reductions were justified through a review of numerous high-impact floods, including but not limited to the cases detailed in Fig. 1 and section 3. The temporal and spatial scales of many extreme precipitation events are smaller than traditional blocking definitions allow for, as the latter are optimized to capture broad and long-lived anticyclones in the mid- to upper troposphere. Longer temporal and spatial scales are better tuned to identify cases of heatwaves and drought than extreme precipitation events.

Table 1 details the two flow reversal metrics [FR in Eq. (1)]. The 500-hPa flow reversal metric identifies regions of $500-\mathrm{hPa}$ easterly geostrophic flow with a minimum zonal wind speed of $-2.5 \mathrm{~m} \mathrm{~s}^{-1}$ (Tibaldi and Molteni 1990). The DT metric searches for a reversal of the DT pressure gradient, normalized by latitude (Table 1) (Pelly and Hoskins 2003). The flow reversal criteria must be met for a minimum of $24 \mathrm{~h}$, reduced from the 3-day minimum required by both Tibaldi and Molteni (1990) and Pelly and Hoskins (2003). The latitudinal-scale requirement is $10^{\circ}$, as opposed to $20^{\circ}$ in both original blocking metrics. We reduced the minimum temporal- and latitudinal-scale criteria because extreme precipitation events often occur on smaller temporal and spatial scales than the large midto upper-tropospheric anticyclones that traditional blocking metrics are designed to identify (Pelly and Hoskins 2003). However, the 24-h temporal requirement was also long enough to capture mid- to uppertropospheric features (e.g., cutoff cyclones, Rossby wave breaks) associated with flow reversal. A longitudinal criterion was not deemed necessary as the 
TABLE 1. Criteria for the modified 500-hPa and DT flow reversal metrics [FR in Eq. (1)] used to calculate 500-hPa and DT EPI, respectively. "Original" requirements refer to the 500-hPa (Tibaldi and Molteni 1990) and DT (Pelly and Hoskins 2003) blocking metrics, respectively.

\begin{tabular}{|c|c|c|c|c|}
\hline $\begin{array}{l}\text { Flow reversal } \\
\text { metric }\end{array}$ & Flow reversal discriminator & $\begin{array}{l}\text { Minimum time scale } \\
\text { requirement }\end{array}$ & $\begin{array}{l}\text { Latitudinal scale } \\
\text { requirement }\end{array}$ & $\begin{array}{l}\text { Longitudinal scale } \\
\text { requirement }\end{array}$ \\
\hline \multirow[t]{2}{*}{$500-\mathrm{hPa}$} & Original and modified: & Original: 3 days & Original: $20^{\circ}$ & Original: $5^{\circ}$ \\
\hline & Easterly geostrophic flow $\leq-2.5 \mathrm{~m} \mathrm{~s}^{-1}$ & Modified: $24 \mathrm{~h}$ & Modified: $10^{\circ}$ & Modified: none \\
\hline \multirow[t]{7}{*}{ DT } & Original: & Original: 3 days & Original: $20^{\circ}$ & Original: $5^{\circ}$ \\
\hline & Reversal of the meridional gradient of & Modified: $24 \mathrm{~h}$ & Modified: $10^{\circ}$ & Modified: none \\
\hline & Modified: & & & \\
\hline & Smaller DT pressure poleward & & & \\
\hline & A meridional DT pressure gradient $>$ & & & \\
\hline & $50 \mathrm{hPa}$ per $10^{\circ}$ latitude, normalized to & & & \\
\hline & a latitude of $45^{\circ} \mathrm{N}$ & & & \\
\hline
\end{tabular}

temporal requirement precludes the identification of longitudinally confined features.

We remapped the ERA-I to a latitude-longitude grid with a $5^{\circ} \times 5^{\circ}$ horizontal grid spacing. This ensured that all finite difference calculations would be performed over the $10^{\circ}$ latitudinal scale required to identify flow reversal (Table 1). To calculate 500-hPa FR in Eq. (1):

- Flow reversal was identified when the zonal component of the geostrophic wind was $\leq-2.5 \mathrm{~m} \mathrm{~s}^{-1}$. At $45^{\circ} \mathrm{N}$, a gradient of $30 \mathrm{~m}$ per $10^{\circ}$ latitude corresponds to an easterly geostrophic wind of approximately $-2.5 \mathrm{~m} \mathrm{~s}^{-1}$. The use of a geostrophic wind threshold allowed the metric to be calculated simultaneously for the $\mathrm{NH}$ and Southern Hemisphere and minimized latitudinal biases with respect to changes in the Coriolis parameter.

- In the tropics (equatorward of $20^{\circ}$ ), very small pressure gradients can result in relatively large geostrophic winds. However, instead of limiting our metric by an arbitrary latitude, we screened for DT pressure values $<150 \mathrm{hPa}$. Excluding these values also helped to minimize an unintended identification of the climatological easterly trade winds.

To calculate DT FR in Eq. (1):

- DT pressure was utilized instead of DT $\theta$, largely to avoid the relatively "noisy" structures of DT $\theta$ associated with tropical convection, which would have obfuscated the results. While this was likely not an issue with the larger temporal and spatial scales of Pelly and Hoskins (2003), our smaller scales necessitated it.

- An upper-tropospheric trough is associated with a depressed tropopause and large DT pressure. Consequently, an equatorward-oriented pressure gradient indicates larger DT pressure values equatorward and represents flow reversal. To search for DT flow reversal that approximates a zonal geostrophic wind component of $\leq-2.5 \mathrm{~m} \mathrm{~s}^{-1}$, we set the DT pressure gradient criterion to $\geq 50 \mathrm{hPa}$ per $10^{\circ}$ latitude normalized to $45^{\circ}$. This was determined after extensive empirical evaluation of many cases and comparisons to our 500-hPa results. The normalization was attained by multiplying the local gradient by the quotient of the Coriolis parameter at $45^{\circ}$ with the Coriolis parameter at the latitude of each gridpoint, to maintain the $\geq 50 \mathrm{hPa}$ per $10^{\circ}$ latitude threshold (Table 1 ).

- The thresholds described above removed features associated with the climatological trade winds and thus we did not screen results by latitude or DT pressure.

Once the flow reversal metrics were calculated, we used Eq. (1) to compute both versions of the EPI for every 6-h time step in our ERA-I dataset (1979-2017).

\section{High-impact flood cases}

\section{a. 2013 Alberta Flood}

Most of the precipitation during the Alberta Flood fell on 19-20 June 2013 (Milrad et al. 2015), which are the focus days of Fig. 2. Both the ERA-I and GPCC generally capture the location and magnitude of the heaviest precipitation (Figs. 2a-d), although accumulations over the flood region of southwestern Alberta (red boxes in Figs. 1a,b) in the ERA-I are 10-20 mm too small compared to GPCC and surface observations (Milrad et al. 2015; Teufel et al. 2017). Nevertheless, ERA-I precipitation (Figs. 2a,b) qualitatively represents the event well.

Figures 2e-h show 500-hPa and DT EPI at 1200 UTC 19 and 20 June, with the dynamic and thermodynamic ingredients on which they are based [Eq. (1)] overlaid. Because the EPI is calculated using a minimum 24-h time criterion, an instantaneous value in the middle of each day can be compared to daily total precipitation. 
19 June 2013

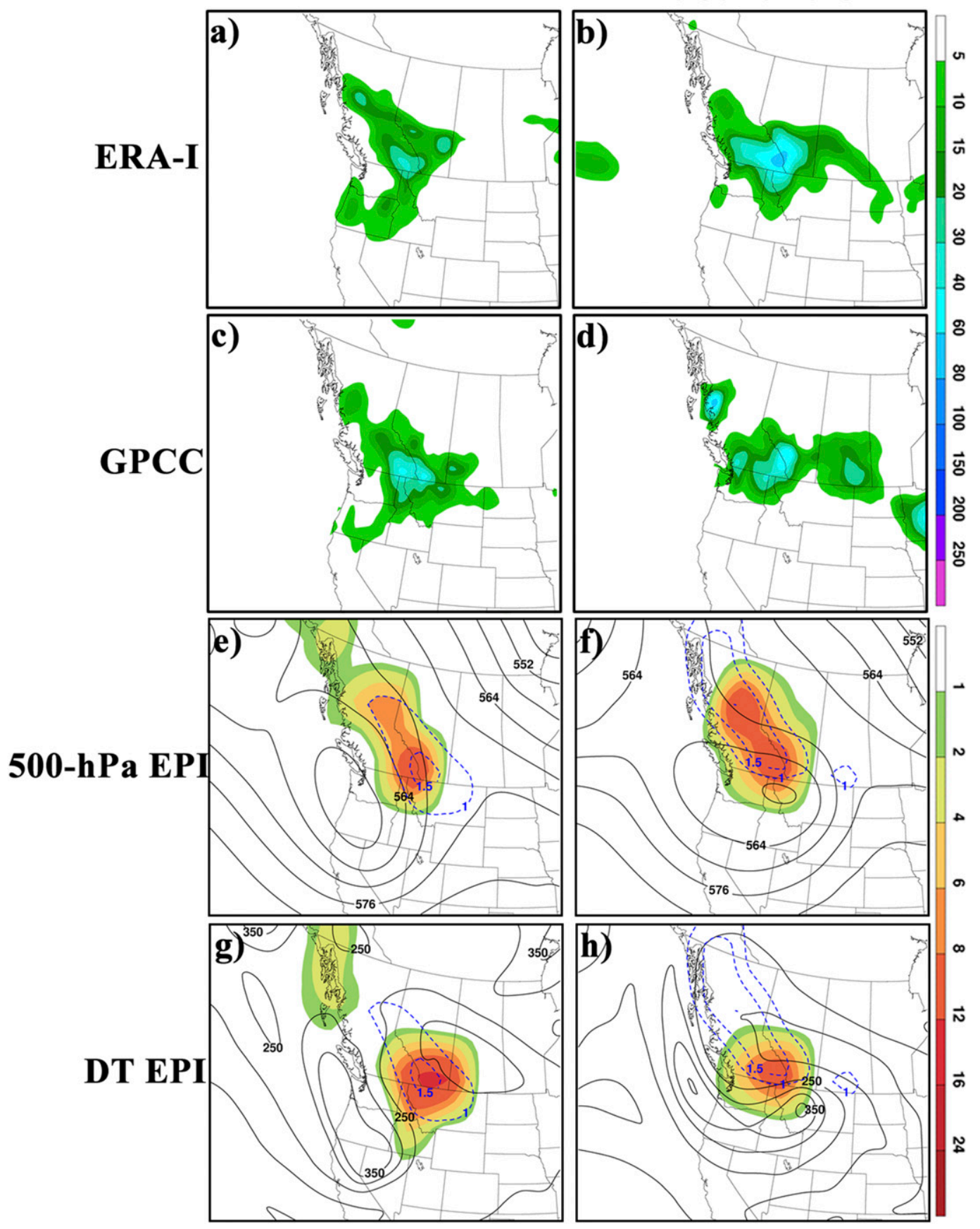

FIG. 2. For the 2013 Alberta Flood: daily precipitation (mm; shaded) for (left) 19 Jun and (right) 20 Jun, as analyzed by the (a),(b) ERA-Interim and (c),(d) GPCC. At 1200 UTC each day, ERA-Interim (e),(f) 500-hPa EPI (shaded), 500-hPa geopotential height (dam; solid black contours), and standardized anomalies of 700-400-hPa layer-averaged equivalent potential temperature $\left[\sigma_{\theta_{e}}\right.$ in Eq. (1), dashed blue contours every $0.5 \sigma$ starting at $+1 \sigma]$; (g), (h) DT EPI (shaded), DT pressure ( $\mathrm{hPa}$; solid black contours), and standardized anomalies $\left[\sigma_{\theta_{e}}\right.$ in Eq. (1)] of $700-400-\mathrm{hPa}$ layer-averaged equivalent potential temperature (dashed blue contours). 
We also compared each 6-h EPI time with 6-h ERA-I precipitation and found good qualitative agreement (not shown). Consistent with Milrad et al. (2015), Figs. 2e and 2f show a closed 500-hPa cyclone located over the northwestern United States, with higher geopotential heights to the north over western Canada, evident of a Rex block. As a result, the 500-hPa flow over Alberta and British Columbia was predominantly easterly on 20 June 2013, the day of the heaviest precipitation in the flood region (Milrad et al. 2015). In addition, positive standardized $\theta_{e}$ anomalies are located over much of western Alberta and eastern British Columbia on both days (Figs. 2e,f).

The combination of easterly geostrophic flow and anomalously warm $\theta_{e}$ results in EPI values $\geq 5$ throughout the flood region (Figs. 2a-f). The 500-hPa EPI accurately identifies the hardest-hit regions in the foothills and mountains of southwestern Alberta and southeastern British Columbia. However, EPI areal extent is considerably larger than that of precipitation, especially in northern Alberta and British Columbia on 20 June. Milrad et al. $(2015,2017)$ found that mesoscale factors such as upslope flow and localized corridors of instability acted to focus the heaviest precipitation over southwestern Alberta. As such, the spatial scales on which the EPI is calculated may be too coarse to precisely match the area of heaviest precipitation on subsynoptic scales.

DT EPI (Figs. 2g,h) results are similar to 500-hPa EPI (Figs. 2e,f), except that the DT EPI maxima on both days have smaller areal extents. Although FR in Eq. (1) is a binary variable, it does not necessarily indicate simultaneous flow reversal in the $500-\mathrm{hPa}$ and DT metrics. In other words, the DT metric can detect flow reversal when the $500-\mathrm{hPa}$ metric does not, and vice versa. Smaller areal extent in DT EPI is a recurring theme throughout our case studies, largely because the DT pressure field exhibits smaller gradient reversal regions than $500-\mathrm{hPa}$ geopotential height (Figs. 2e-h). These results are consistent with Pelly and Hoskins (2003); that is, DT gradient reversal metrics tend to be more precise and able to identify smaller flow reversal regions than those based on $500-\mathrm{hPa}$ geopotential height.

\section{b. 2016 western Europe Flood}

The late May-early June 2016 western Europe Flood (Philip et al. 2018) caused more than 3 billion USD in insured losses and featured extensive flooding in France, Belgium, and parts of Germany (Munich RE 2017). The heaviest precipitation occurred on 29-30 May (Figs. 3a-d in association with a midto upper-tropospheric cyclone located over central
France (Figs. 3e-h). The 2-day totals from the GPCC (Figs. 3c,d) show 70-120 mm across western Germany, much of Belgium, and northern France. ERA-I precipitation (Figs. 3a,b) reasonably matches GPCC (Figs. 3c,d), although it underestimates amounts over parts of western Germany on 29 May.

The 500-hPa EPI results for this event are somewhat mixed. While the 500-hPa EPI matches the extreme precipitation location on 30 May (Fig. 3f), there is no 500-hPa EPI maximum near the heavy precipitation region on 29 May (Fig. 3e). The absence of 500-hPa EPI on 29 May is related to the near-zero meridional geopotential height gradient in that region (Fig. 3e). In contrast, on 30 May (Fig. 3f) there is a closed 500-hPa cyclone centered on the France-Germany border.

DT EPI clearly exhibits better performance for this case than 500-hPa EPI. First, on 29 May, a DT EPI maximum is collocated with the heaviest precipitation (Figs. 3c,g). Second, DT EPI spatial extent on 30 May is considerably smaller than its $500-\mathrm{hPa}$ counterpart (Figs. 3f,h). As in the Alberta Flood (Fig. 2), the better precision and accuracy of DT EPI is related to the smaller region in which there is a DT pressure gradient reversal. Furthermore, at 1200 UTC 29 May, the DT pressure gradient reverses whereas the $500-\mathrm{hPa}$ geopotential height gradient does not (Figs. 3e,g).

\section{c. 2000 southern Alpine Flood}

Figure 4 details the October 2000 southern Alpine Flood, which primarily affected southern Switzerland and northern Italy. This event caused extensive flooding of Lago Maggiore, located on the southern edge of the Swiss Alps and was detailed by Lenggenhager et al. (2019). While the Lago Maggoire flooding was caused by three distinct extreme precipitation events between 15 September and 15 October, more than $60 \%$ of that period's rainfall fell in the third and longest duration event, during 10-16 October (Lenggenhager et al. 2019). We focus on the third event here, specifically 14 15 October when more than $120 \mathrm{~mm}$ of precipitation was recorded (Lenggenhager et al. 2019). During this period, an omega block pattern is evident across much of Europe (Figs. 4e,f).

Figures $4 a-d$ show that the ERA-I and GPCC accurately capture the location of the heaviest precipitation over the southern Alps, although the ERA-I slightly underestimates the maximum amounts over Switzerland on 14 October (Figs. 4a,c). On 14 October, 500-hPa and DT EPI (Figs. 4e,g) correctly identify the region of heaviest precipitation (Figs. 4a,c), as both 500-hPa geopotential height and DT pressure exhibit gradient reversals in the presence of anomalously large $\theta_{e}$ (Figs. 4e,g). On 15 October, however, the 500-hPa 
29 May 2016

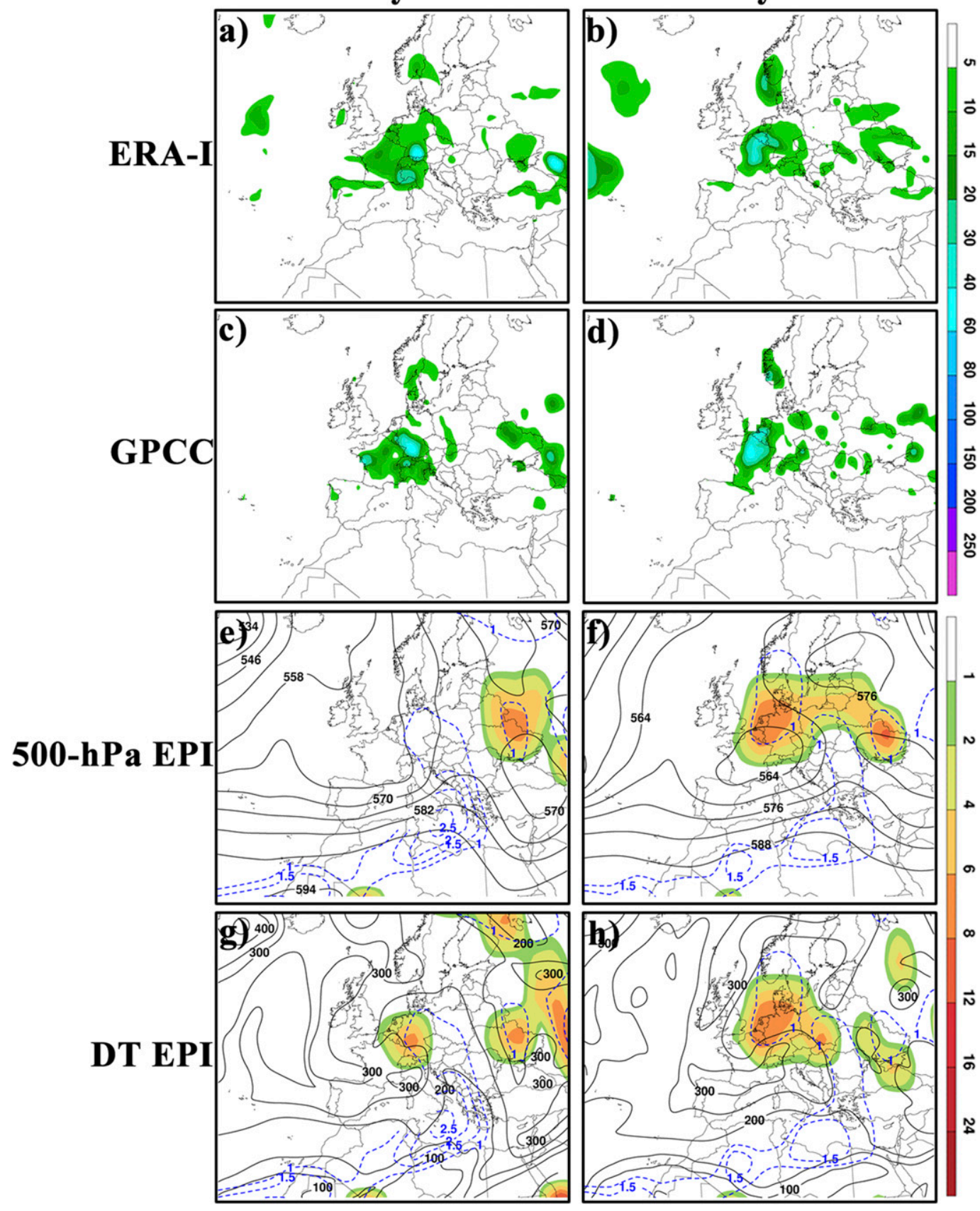

FIG. 3. As in Fig. 2, but for 29-30 May 2016 during the western Europe Flood.

EPI maximum is located farther north over France, Belgium, and Germany (Fig. 4f), where less precipitation fell (Figs. 4b,d). This is likely due to a slight location shift of the 500-hPa geopotential height gradient reversal (Fig. 4f). As in the 2016 western Europe Flood, DT EPI accurately identifies the region of heaviest precipitation throughout the event (Figs. 4g,h). On 15 October (Fig. 4h), DT EPI also exhibits a smaller maximum over northern France, near the 500-hPa EPI bullseye (Fig. 4f). The location differences between the two EPI versions on 15 October are related to the slightly offset locations of flow reversal (Figs. 4f,h).

\section{d. 2016 Louisiana Flood}

In August 2016, heavy precipitation for several days caused severe flooding across Louisiana, particularly in 


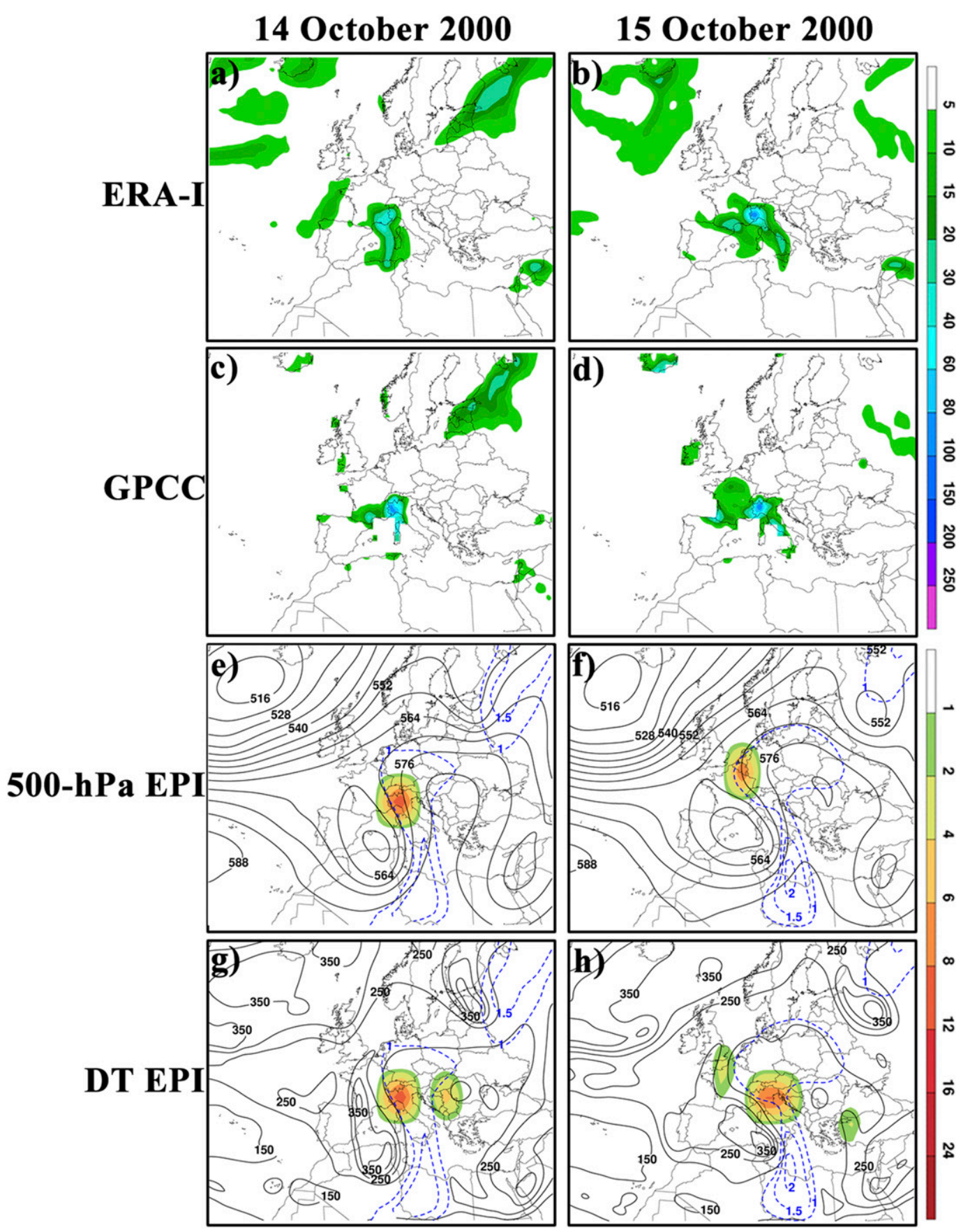

FIG. 4. As in Fig. 2, but for 14-15 Oct 2000 during the southern Alpine Flood.

the Baton Rouge area (Wang et al. 2016). The two most extreme precipitation days, 13-14 August, saw approximately $200 \mathrm{~mm}$ of rainfall across much of the state (Figs. 5a-d). Wang et al. (2016) found that the synoptic-scale pattern was characterized by a large upper-tropospheric ridge over most of the eastern United States and a weak warm-core cyclonic disturbance located in the northern Gulf of Mexico.
Figures $5 \mathrm{e}-\mathrm{h}$ show that $500-\mathrm{hPa}$ EPI did not accurately diagnose the extreme precipitation over Louisiana, but DT EPI exhibited promise, especially on 14 August (Fig. 5h). This event is different from the other three case studies in that the mid- to uppertropospheric cyclone associated with the warm-core disturbance was quite weak and spatially fine. Therefore, our relatively coarse reanalysis grids had some 


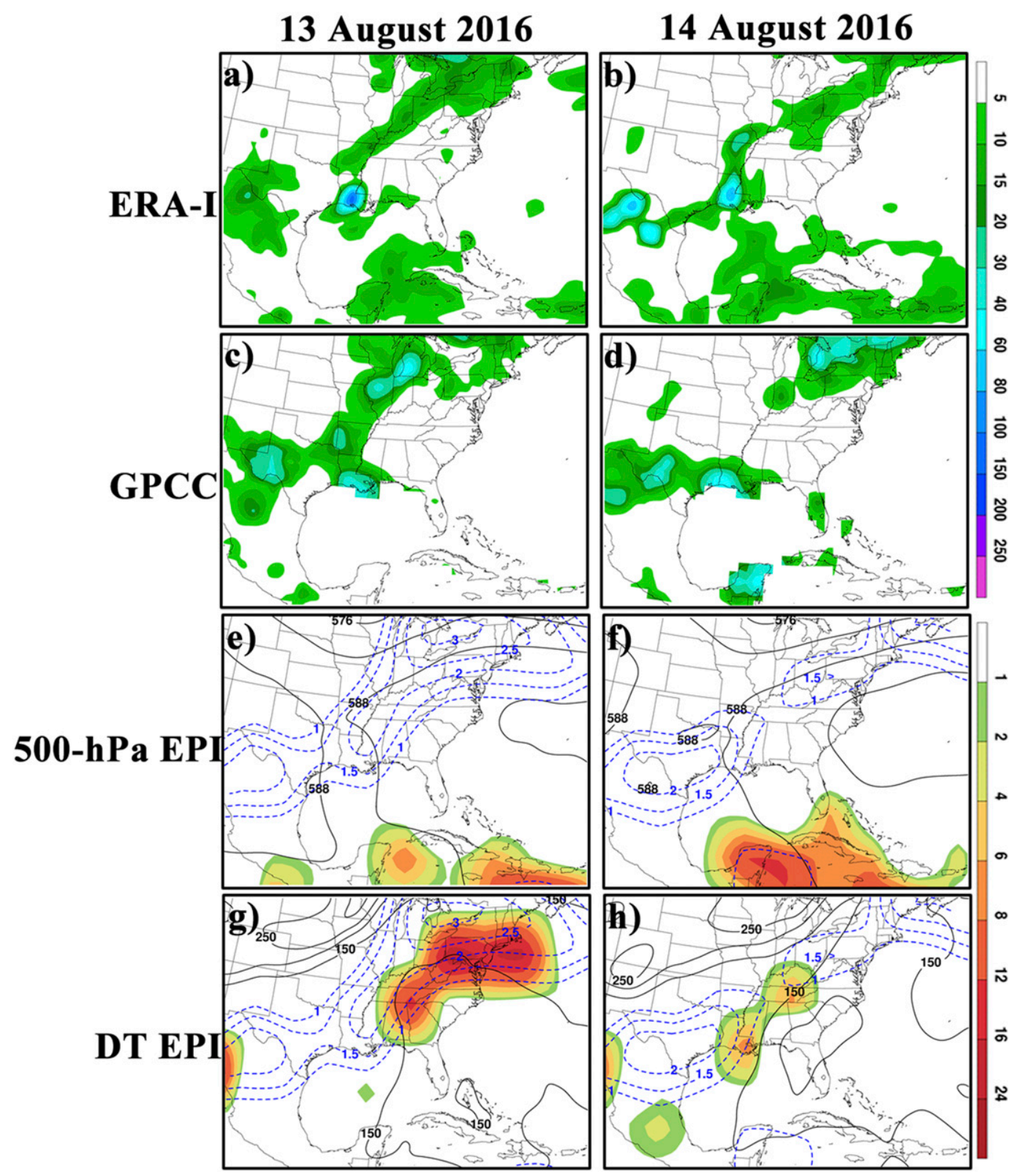

FIG. 5. As in Fig. 2, but for 13-14 Aug 2016 during the Louisiana Flood.

trouble detecting the flow reversal, especially for $500-\mathrm{hPa}$ EPI (Figs. 5e,f). However, the ability of DT EPI to accurately diagnose part of the event (Fig. 5h) suggests that minor modifications to the spatial criteria in Table 1 would enable the EPI to be used for smaller-scale warmcore (i.e., tropical and subtropical) disturbances such as the one that caused the Louisiana Flood. We tested a less coarse version of the EPI for this event and the flooding associated with the remnants of Hurricane Harvey (2017) over Texas, and early results were promising (not shown).

Overall, the four cases presented here demonstrate that the EPI can detect the location of extreme precipitation associated with flow reversal across a relatively wide range of event types (e.g., Rex and omega blocks, closed/cutoff upper-tropospheric cyclones) and seasons. In general, DT EPI offers better precision than 500-hPa EPI in terms of location and areal extent. We examined many highimpact midlatitude floods associated with flood reversal and found that DT EPI typically matches or exceeds the accuracy and precision of 500-hPa EPI (not shown). We again remind the reader that any magnitude differences between 500-hPa and DT EPI are due to the number of grid points at which 
flow reversal is detected over each 24-h running mean period.

\section{Flow reversal and EPI climatologies}

\section{a. Flow reversal}

Figure 6 shows seasonal frequency climatologies of the two flow reversal metrics [FR in Eq. (1)]. Overall, the DT metric exhibits a substantially larger number of events throughout the NH mid- and high latitudes, supporting our assessment that it is a more sensitive and robust metric. This is largely because, for most midlatitude synoptic-scale systems, the intensity of a geopotential height perturbation must be maximized on the DT. In winter, both the 500-hPa (Fig. 6a) and DT (Fig. 6b) climatologies highlight the far North Pacific and North Atlantic as the largest flow reversal frequency maxima in the $\mathrm{NH}$, especially across the Bering Sea, Gulf of Alaska, and near Iceland. These regions were also found as winter $\mathrm{NH}$ maxima of 500-hPa closed/cutoff cyclones (Bell and Bosart 1989, all mentions henceforth refer to their Fig. 2) and CWB (Bowley et al. 2019, all CWB mentions henceforth refer to their Fig. 6), suggesting that both are important subsets of winter flow reversal events. Martius et al. (2007) also found an extension of North Atlantic Rossby wave break frequency maxima into Europe, which we see represented as secondary $\mathrm{NH}$ flow reversal maxima (Figs. 6a,b). The DT metric also exhibits secondary maxima over the U.S. Pacific Northwest and parts of central Asia (Fig. 6b).

In spring, the flow reversal metrics exhibit similar maxima (Figs. 6c,d) to winter over the Bering Sea, Gulf of Alaska, and far North Atlantic. Similar results were reported in the closed/cutoff cyclone (Bell and Bosart 1989) and CWB (Bowley et al. 2019) climatologies. Secondary maxima are also observed over much of Europe, including the Alps (Figs. 6c,d) and Rockies in the DT metric (Fig. 6d). The DT metric also highlights the subtropical jet stream through high frequency bands in the North Pacific and North Atlantic (Fig. 6d). All of these secondary maxima were found as secondary closed/cutoff cyclone hotspots (Bell and Bosart 1989), and regions of frequent AWB (Bowley et al. 2019, all AWB mentions henceforth refer to their Fig. 5). Furthermore, both the Alberta and western Europe Floods occurred during spring in regions highlighted by regional flow reversal maxima, especially the DT metric (Fig. 6d).

In summer (Figs. 6e,f), both flow reversal metrics identify maxima over the subtropical oceans (Figs. 6e,f). The DT metric also exhibits a regional frequency maximum in the northern Gulf of Mexico (Fig. 6f), the region of the 2016 Louisiana Flood. Overall, our regional summer flow reversal maxima (Fig. 6e,f) are most similar to the closed/cutoff cyclone climatology (Bell and Bosart 1989) in the mid- and high latitudes, and to the AWB climatology in the subtropics (Bowley et al. 2019).

Finally, autumn (Figs. 6g,h) is qualitatively like spring, with the largest frequency maxima located within the Bering Sea, Gulf of Alaska, and far North Atlantic. These areas match autumn closed/cutoff cyclone (Bell and Bosart 1989) and CWB (Bowley et al. 2019) maxima. Secondary maxima are observed across parts of Europe and Asia, particularly in the DT metric (Fig. 6h), similar to AWB hotspots (Bowley et al. 2019). The Alps, where the October 2000 southern Alpine Flood (Lenggenhager et al. 2019) occurred, is also a notable secondary frequency maxima in both flow reversal metrics (Figs. 6g,h). Finally, as in the other three seasons, especially spring (Fig. 6d) and summer (Fig. 6f), the autumn climatology (Fig. 6h) highlights bands of flow reversal occurrence maxima within or near the location of the subtropical jet across the NH.

\section{b. 500-hPa EPI}

To identify EPI hotspots across the NH midlatitudes, Figs. 7 and 8 show seasonal frequency of exceedance climatologies of EPI $\geq 1$ and EPI $\geq 5$ for $500-\mathrm{hPa}$ and DT EPI, respectively. Higher thresholds (i.e., EPI $\geq 10$ ) are qualitatively similar, but feature progressively smaller occurrence frequencies. For 500-hPa EPI, NH winter generally has the smallest total occurrence frequency of any season, especially for EPI $\geq 5$ (Fig. 7b). This is likely due in part to $\partial r_{s} / \partial p$ being smallest in winter. Nevertheless, the winter climatologies exhibit NH EPI maxima located across parts of the far North Pacific and North Atlantic, with the North Pacific seeing more frequent events over a larger area (Figs. 7a,b). Secondary EPI maxima are found near the west coast of North America as well as much of western and southern Europe (Figs. 7a,b). Winter is the wet season along the west coast of North America, with most precipitation occurring in association with atmospheric rivers (ARs) of subtropical water vapor transport (e.g., Ralph et al. 2017). A brief evaluation (not shown) of the EPI's ability to detect the large poleward moisture transport composite events of Roberge et al. (2009) suggests that the EPI can successfully identify extreme precipitation associated with ARs, especially toward western Canada and the Gulf of Alaska.

During spring, some of the largest 500-hPa EPI $\geq 5$ frequencies (Fig. 7d) are again found across the far North Pacific and North Atlantic. Unlike in winter, the 

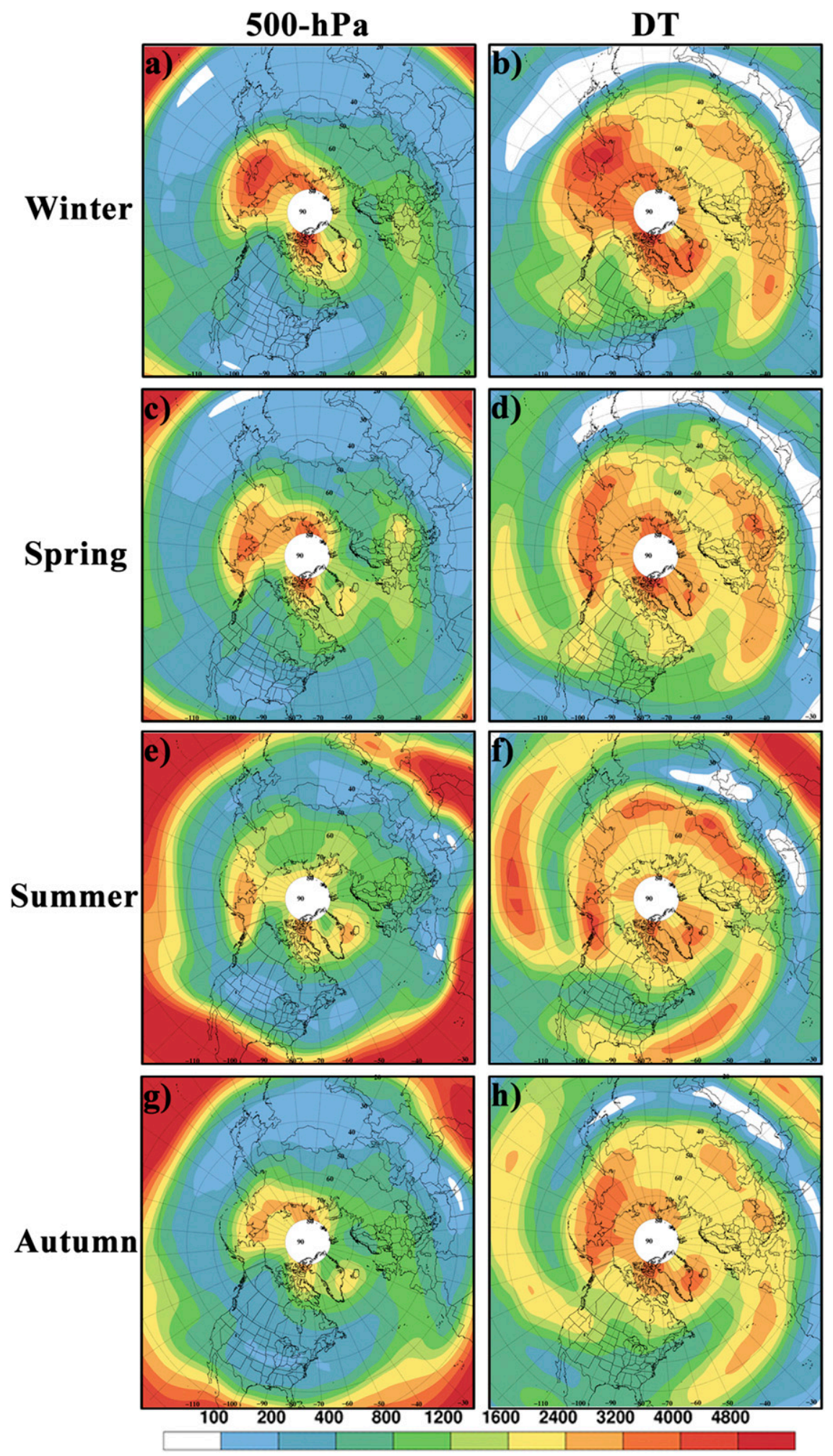

FIG. 6. ERA-Interim climatological (1979-2017) occurrence frequency (shaded) of (left) 500-hPa and (right) DT flow reversal [FR in Eq. (1)] in (a),(b) winter (December-February), (c),(d) spring (March-May), (e),(f) summer (June-August), and (g),(h) autumn (SeptemberNovember). While the color scheme here is the same as that for the EPI climatologies in Figs. 7 and 8 , the color bar values are different. 

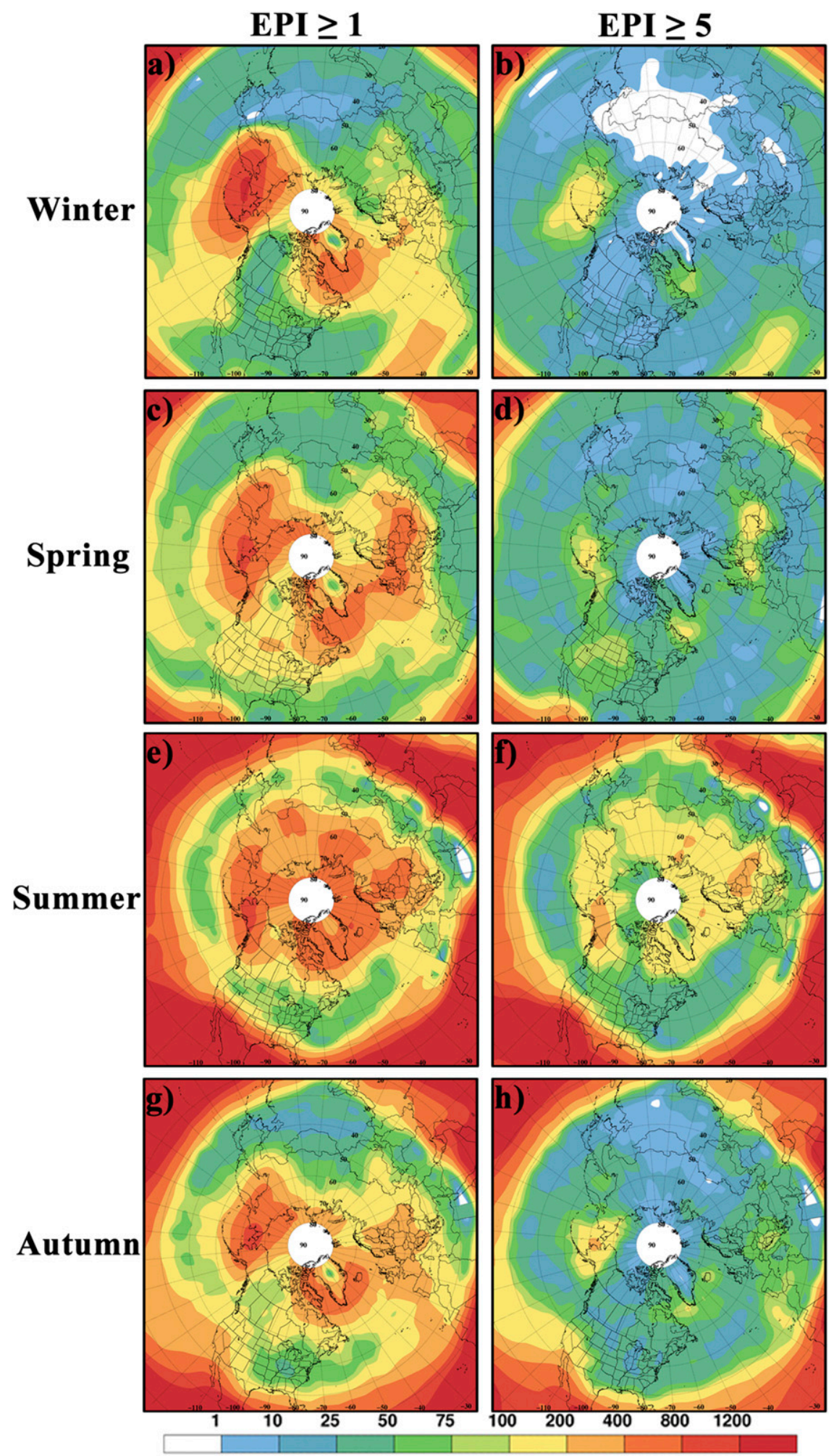

FIG. 7. ERA-Interim climatological (1979-2017) occurrence frequency (shaded) of 500-hPa EPI (left) $\geq 1$ and (right) $\geq 5$ for (a),(b) winter (December-February), (c),(d) spring (March-May), (e),(f) summer (June-August), and (g),(h) autumn (September-November). 

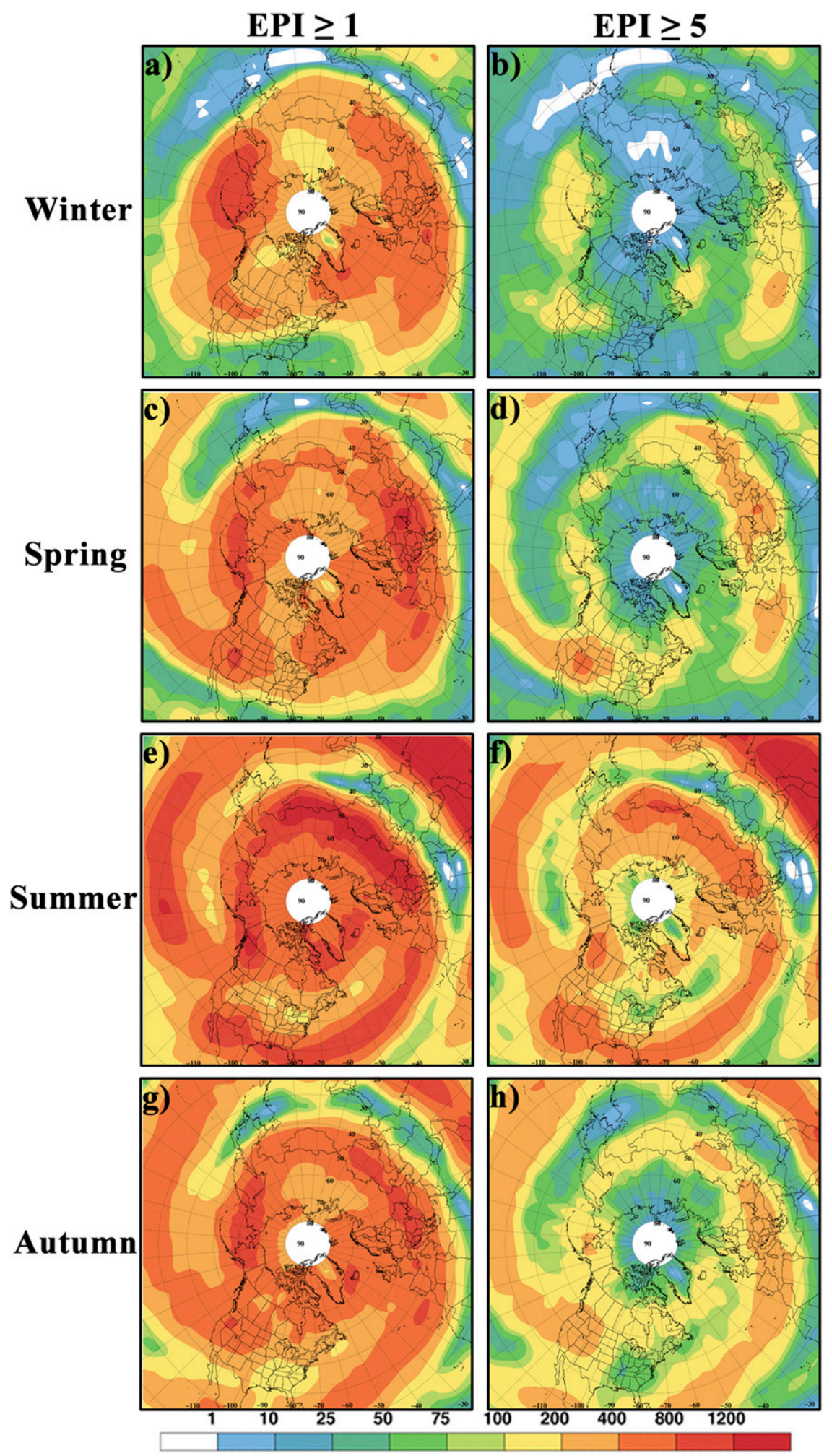

FIG. 8. As in Fig. 7, but for DT EPI. 
maxima over Europe and the Rockies are similar in magnitude to those over the oceanic storm tracks (Figs. 7c,d), matching our flow reversal results (Fig. 6c), as well as the closed/cutoff cyclone (Bell and Bosart 1989) and AWB (Bowley et al. 2019) climatologies. These results suggest that frequent EPI events over Europe and the Rockies are likely associated with a closed/cutoff cyclone and/or an AWB. Europe and the Canadian Rockies also feature two of our billion dollar (U.S. dollars) flood catastrophes (2013 Alberta and 2016 western Europe Floods), both of which occurred in spring.

In summer, the far North Pacific and North Atlantic 500-hPa EPI frequency maxima retreat poleward from their winter and spring positions (Figs. 7e,f). Other regional frequency maxima in summer are located across northern Europe and Asia (Figs. 7e,f). Summer is also the season in which the largest number of 500-hPa EPI $\geq 5$ events occur poleward of the subtropics (Fig. 7f). Because summer does not exhibit larger flow reversal frequencies than other seasons (Fig. 6e), this is likely due to the more anomalous (standardized by season) $\theta_{e}$ during summer, and to a lesser extent larger $\partial r_{s} / \partial p$. Moore et al. (2015) found similar results as their extreme precipitation events associated with weaker moisture transport/jet streams (such as those more prevalent in summer) tended to have more anomalous heat and moisture.

The 500-hPa EPI autumn climatology (Figs. 7g,h) is similar to spring (Figs. 7c,d), although the regional frequency maxima over the Rockies and Alps are slightly weaker. Similar results are observed over the Alps for our 500-hPa flow reversal frequencies (Figs. 6c, g) and over both regions for closed/cutoff cyclones (Bell and Bosart 1989). However, the decreases in EPI $\geq 5$ occurrence frequency over the Rockies and Alps between spring and autumn are opposite to the AWB climatology of Bowley et al. (2019); this contradiction is because their AWB climatology used a DT metric (section 4c).

\section{c. DT EPI}

The DT EPI seasonal climatologies (Fig. 8) are quite different from 500-hPa EPI (Fig. 7), particularly in terms of magnitude. First, DT EPI identifies substantially more overall and $\geq 5$ EPI events throughout the $\mathrm{NH}$ midlatitudes in all seasons, again suggesting that the DT EPI is a more sensitive parameter for detecting flow reversal (Pelly and Hoskins 2003). Second, the magnitudes of DT EPI $\geq 5$ frequency maxima over the Rockies and Alps match or exceed values over the far North Pacific and North Atlantic, particularly during spring and autumn (Fig. 8). This suggests that AWB (Bowley et al. 2019) and closed/cutoff cyclones (Bell and Bosart 1989), in combination with anomalously warm moist air transport from the Gulf of
Mexico and Mediterranean, respectively, are important subsets and causes of DT EPI events whose frequency may be underestimated by 500 -hPa EPI. It is not a coincidence that numerous recent billion dollar flood disasters associated with flow reversal (section 1) have occurred in those regions.

In winter (Figs. 8a,b), large DT EPI maxima are located across the far North Pacific and North Atlantic, as well as throughout the subtropical jet bands of the eastern North Pacific and eastern North Atlantic/Southern Europe. The northern maxima are similar to the closed/cutoff cyclone (Bell and Bosart 1989) and CWB (Bowley et al. 2019) climatologies, while the subtropical areas somewhat mirror AWB maxima (Bowley et al. (2019). Secondary winter maxima are observed across central Asia and western United States (Figs. 8a,b).

During spring (Figs. 8c,d) and autumn (Figs. 8g,h), regional DT EPI frequency maxima are found over the Rockies and Alps, particularly for EPI $\geq 5$. These are both regions of frequent DT flow reversal (Figs. 6d,h) and AWB (Bowley et al. 2019). In addition, the DT EPI $\geq 5$ frequency maxima over the Rockies and Alps are quite similar in magnitude between spring and autumn, which contrasts with the 500-hPa EPI results (section 4b) but does not contradict Bowley et al. (2019). The better agreement of DT EPI with the Bowley et al. (2019) climatologies is likely due to their defining wave breaks based on DT metrics.

Finally, the summer regional DT EPI frequency maxima over the far North Pacific and North Atlantic (Figs. 8e,f) are located poleward of their locations in cooler seasons. Large frequency maxima are also observed throughout much of Eurasia, similar to the closed/cutoff cyclone climatology (Bell and Bosart 1989). In general, our summer EPI maxima are least similar of any season to the wave break climatologies (Bowley et al. 2019), suggesting that summer large EPI events are likely caused by a combination of closed/cutoff cyclones and omega/Rex blocks.

\section{Accuracy evaluation}

\section{a. High-impact flood cases}

To quantify the EPI's utility in pinpointing the locations of extreme precipitation associated with flow reversal, we calculated Pearson product-moment correlation coefficients between both versions of EPI and ERA-I daily precipitation, for the four case studies detailed in section 3. The Pearson correlation coefficients for each day shown in Figs. 2-5 are displayed in Table 2. Supporting the results from Fig. 2, correlation coefficients for $500-\mathrm{hPa}$ and DT EPI are similar on both days of the Alberta Flood (Table 2). Furthermore, all correlation coefficients for the 
TABLE 2. Pearson product-moment correlation coefficients between ERA-Interim daily precipitation and 500-hPa EPI and DT EPI on each day shown in Figs. 2-5 for the 2013 Alberta, 2016 western Europe, 2000 southern Alpine, and 2016 Louisiana floods, respectively. The EPI values used are from 1200 UTC on each day.

\begin{tabular}{lcccc}
\hline \hline & 2013 Alberta Flood & 2016 western Europe Flood & 2000 southern Alpine Flood & 2016 Louisiana Flood \\
\hline 500-hPa EPI: day 1 & 0.55 & 0 & 0.58 & 0 \\
500-hPa EPI: day 2 & 0.55 & 0.33 & 0 & 0 \\
DT EPI: day 1 & 0.5 & 0.15 & 0.48 & 0 \\
DT EPI: day 2 & 0.58 & 0.48 & 0.65 & 0.3 \\
\hline
\end{tabular}

Alberta Flood are $\geq 0.5$, exemplifying the potential utility of the EPI in diagnosing extreme precipitation in a larger population of Rex block patterns.

As discussed in section 3b, DT EPI outperformed 500-hPa EPI with respect to the location of the heaviest precipitation in the 2016 western Europe Flood. This was especially true on 30 May 2016 (Fig. 3). Correlation coefficients in Table 2 support these assertions, as the $500-\mathrm{hPa}$ EPI correlation is 0 and 0.33 on 29 and 30 May, respectively, while the DT EPI correlation is 0.15 and 0.48 , respectively. For the 2000 Alpine Flood (section 3c), 500-hPa EPI does not properly diagnose precipitation on the second day (15 October 2000; Fig. 4). Table 2 shows that although correlations for 500-hPa and DT EPI are similar on day 1 (14 October 2000), DT EPI greatly outperforms its counterpart on day 2. DT EPI's relatively large correlations across various flow regimes, such as the closed uppertropospheric cyclone in the western Europe Flood (Fig. 1c) and omega block in the southern Alpine Flood (Fig. 1e), exemplify the potential utility of the EPI in diagnosing extreme precipitation events across a wide variety of patterns.

Finally, both EPI metrics have difficulty discerning the precipitation associated with the Louisiana Flood on 13 August 2016, primarily due to the weakness of the midto upper-tropospheric cyclonic disturbance over the Gulf of Mexico (Wang et al. 2016), and the relatively coarse latitudinal scale on which our flow reversal metrics are calculated (section $3 \mathrm{~d}$ ). This assertion is supported by the correlation values of zero (Table 2). However, on 14 August 2016, DT EPI does a respectable job identifying the heavy precipitation over Louisiana (Figs. 5d,h), with a correlation of 0.3 (Table 2). Overall, the correlations in Table 2 support the idea that the EPI can be useful in detecting the location of heaviest precipitation associated with flow reversal, and that DT EPI offers better accuracy and precision than 500-hPa EPI does.

\section{b. EPI climatologies}

To briefly evaluate how well the EPI identifies extreme precipitation events on a climatological basis, Fig. 9 shows seasonal occurrence frequencies of ERA-I daily $(24 \mathrm{~h})$ precipitation totals $\geq 1$ in. $(25.4 \mathrm{~mm})$. This threshold was identified by Sukovich et al. (2014) as a key metric used to evaluate QPF at WPC. We also evaluated the $3 \mathrm{in} .(76.2 \mathrm{~mm})$ and $6 \mathrm{in} .(152.4 \mathrm{~mm})$ thresholds (not shown); results were qualitatively similar in terms of spatial distributions and locations, but the higher thresholds had smaller frequency magnitudes.

In winter (Fig. 9a), extreme precipitation events occur most frequently within the North Pacific and Western North Atlantic storm tracks, the west coast of North America, and throughout the Southeast United States. Secondary maxima are observed across the Alps and parts of central Asia (Fig. 9a). Over the North Pacific (Fig. 9a), extreme precipitation occurs most frequently equatorward of the EPI maxima (Figs. 7a,b and 8a,b), suggesting that in winter most extreme precipitation events over that region are not associated with flow reversal. This coincides with the North Pacific polar jet's strongest season; strong westerly jets are less conducive to flow reversal regimes such as cutoff cyclones and Rex blocks. Another region in winter where the EPI and extreme precipitation climatologies do not match is the southeast United States, suggesting that winter extreme precipitation events there are largely not associated with flow reversal. However, winter EPI (Figs. 7b, 8b) and extreme precipitation (Fig. 9a) frequencies are a better qualitative match in the Gulf of Alaska and near the northwest coast of North America, suggesting that more extreme precipitation events there are associated with flow reversal, likely closed/cutoff cyclones (Bell and Bosart 1989) and/or CWB (Bowley et al. 2019).

In the transition seasons of spring and autumn (Figs. 9b,d), extreme precipitation events are slightly less frequent across the North Pacific and North Atlantic. In addition, the frequency of extreme events decreases along the California and Oregon coasts, and is largely limited to the coasts of Washington, British Columbia, and Alaska. DT EPI (Fig. 8) does a particularly good job of highlighting these regions, which coincide with more frequent closed/cutoff cyclones (Bell and Bosart 1989) and AWB (Bowley et al. 2019) in spring and autumn. Finally, DT EPI in particular suggests that more extreme precipitation events in the 

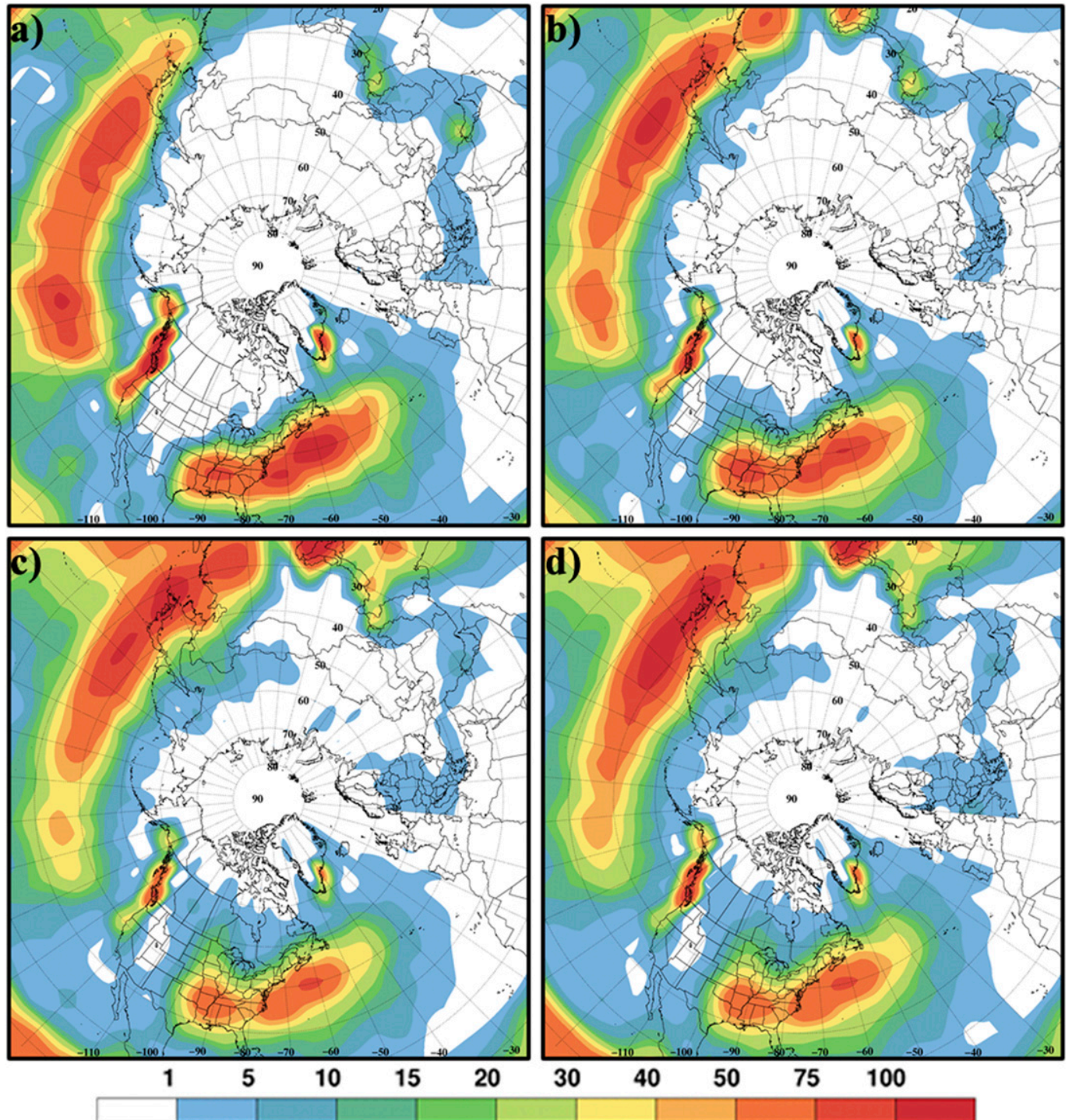

FIG. 9. ERA-Interim climatological (1979-2017) occurrence frequency (shaded) of daily precipitation $\geq 1 \mathrm{in}$. $(25.4 \mathrm{~mm})$ in (a) winter (December-February), (b) spring (March-May), (c) summer (June-August) and (d) autumn (September-November).

eastern United States are associated with flow reversal in spring (Figs. 8d,9b) than in winter (Figs. 8b,9a) and autumn (Figs. 8h,9d).

Finally, the summer extreme precipitation climatology (Fig. 9c) shows qualitative similarities to DT EPI over western Canada and the southeast United States (Figs. 8f, 9c). The poleward shift of extreme events in Europe (Fig. 9c) compared to other seasons mimics the shift in DT EPI frequency (Figs. 8e,f), and the frequency maximum near Mongolia is also similar. On a climatological basis, DT EPI generally provides a more accurate description of where extreme precipitation events tend to occur within the
NH midlatitudes than 500-hPa EPI does, as in our case study results.

\section{Discussion and conclusions}

In this study, a coupled dynamic-thermodynamic metric (EPI) was developed to diagnose extreme precipitation events associated with mid- to uppertropospheric flow reversal. Two versions of the EPI (500-hPa and DT) were tested using the ERA-I reanalysis and found to be useful in identifying the location and areal extent of heaviest precipitation. Through multiple case studies of high-impact floods 
(section 3) associated with several types of flow reversal regimes (i.e., Rex blocks, omega blocks, cutoff cyclones), we demonstrated that the EPI can consistently identify the locations of extreme precipitation. While both EPI versions are effective, DT EPI offers better precision, likely owing to the higher reliability of DT metrics in identifying flow reversal (e.g., Pelly and Hoskins 2003). Correlations between EPI and precipitation for the four high-impact floods (section 5a) show that DT EPI exhibits consistently better accuracy than 500-hPa EPI in terms of location and extent of extreme precipitation.

Our flow reversal and EPI climatologies (section 4) show that EPI frequency maxima locations vary somewhat by season, but the largest EPI frequencies occur over the far North Pacific and North Atlantic, associated with regional maxima of closed/cutoff cyclones (Bell and Bosart 1989) and CWB (Bowley et al. 2019). Important secondary maxima are observed near the Rockies, Alps, and central Asia, particularly in the transition seasons of spring and autumn. Flow reversal in these regions is associated with regional maxima in closed/cutoff cyclones (Bell and Bosart 1989) and AWB (Bowley et al. 2019).

As in the Bell and Bosart (1989) and Bowley et al. (2019) climatologies, there are large regionally dependent seasonal variations in our flow reversal and EPI metrics. In addition, while closed/cutoff cyclones and wave breaks are important subsets of our flow reversal and EPI events, other regimes (e.g., Rex and omega blocks) are also diagnosed by our metrics. Another issue with the EPI is that while it can successfully detect most extreme precipitation events associated with flow reversal, only a relatively small percentage of extreme precipitation events fall into this category. Therefore, the EPI is much more useful in diagnosing individual events than it is for extreme precipitation climatologies. This is borne out by the more impressive accuracy evaluation results throughout our case studies (sections 3 and 5a) compared to our climatologies (section $5 b$ ).

As such, future work should investigate the EPI from a predictability standpoint, with a primary goal of improving medium-range (3-10 day) QPF of extreme events associated with flow reversal. By incorporating the EPI into operational deterministic and ensemble NWP models, it may help improve human-produced QPF accuracy and flood alert lead times. The added value of the EPI should particularly be realized in probabilistic human forecasts addressing the likelihood and locations of extreme precipitation associated with flow reversal. Predictability work should use multiple verification methods such as
Pearson correlations (section 5a) and object-oriented verification, in which a computer algorithm compares the shape and magnitude of the QPF distribution to observed precipitation. Finally, the use of ensemble reforecasts in retrospective mode may further facilitate applications of the EPI to QPF.

Another issue with respect to future work is that extreme precipitation events have increased in frequency and intensity (e.g., Rahmstorf and Coumou 2011; Coumou and Rahmstorf 2012). Specifically, anthropogenic warming may affect the frequency and intensity of extreme precipitation through both thermodynamic and dynamic mechanisms. The thermodynamics link, which has been long understood, is based on observed and projected increases in atmospheric water vapor (e.g., Groisman et al. 2012; Kunkel et al. 2013; Fischer and Knutti 2015).

While dynamic linkages to extreme precipitation changes are more uncertain, they have been widely investigated in recent years. Some research has associated rapid Arctic warming [Arctic amplification (AA)] with changes in the NH midlatitude jet stream (e.g., Cohen et al. 2014; Screen and Simmonds 2014). Francis and Vavrus (2012, 2015) found a correlation between AA and weaker zonal upper-tropospheric winds in the midlatitudes, indicating a "wavier" jet stream, which would theoretically be conducive to slowerpropagating flow patterns. Dynamic analyses of the quasi-resonance of mid- to upper-tropospheric waves also demonstrated that circulation features in the $\mathrm{NH}$ midlatitudes may be becoming more amplified with reduced zonal propagation speeds, particularly in the warm season (Petoukhov et al. 2013; Coumou et al. 2014, 2015; Hoskins and Woollings 2015; Kornhuber et al. 2017).

However, linkages between AA and midlatitude jet changes are still controversial, as weaker midlatitude zonal winds may be artifacts of methodology and correlations may not indicate causation (Barnes 2013; Barnes and Polvani 2015; Barnes and Screen 2015; Overland et al. 2015). In a more general study of projected extreme precipitation changes, Pfahl et al. (2017) stress that while thermodynamic changes are well understood, reducing uncertainties in projections of dynamic changes is key to better understanding regional trends in extreme precipitation.

Our flow reversal metrics and EPI may be useful to help understand trends and projections in flow patterns and extreme precipitation. In addition, the EPI may be used to investigate the sensitivity of projected changes to dynamic and thermodynamic ingredients, respectively. As such, the flow reversal metrics and EPI have applications to both operational forecasting and climate 
science, which we plan to investigate widely in future research.

Acknowledgments. This study was funded by a research grant from the Bermuda Institute of Ocean Sciences (BIOS) Risk Prediction Initiative 2.0 (RPI 2.0). We thank Dr. Mark Guishard of BIOS for facilitating funding and continued support of our research. The authors would also like to thank NCAR for making the ERA-Interim and NCEP-NCAR reanalysis data accessible, as well as the Deutscher Wetterdienst (German Weather Service) for providing access to GPCC daily precipitation data. Finally, many thanks to the three anonymous reviewers and editor Dr. Lynn McMurdie, for their helpful comments toward earlier versions of this manuscript.

\section{REFERENCES}

Abatzoglou, J. T., 2016: Contribution of cutoff lows to precipitation across the United States. J. Appl. Meteor. Climatol., 55, 893899, https://doi.org/10.1175/JAMC-D-15-0255.1.

Barnes, E. A., 2013: Revisiting the evidence linking Arctic amplification to extreme weather in midlatitudes. Geophys. Res. Lett., 40, 4734-4739, https://doi.org/10.1002/ grl.50880.

- , and L. M. Polvani, 2015: CMIP5 projections of Arctic amplification, of the North American/North Atlantic circulation, and of their relationship. J. Climate, 28, 5254-5271, https:// doi.org/10.1175/JCLI-D-14-00589.1.

_ the midlatitude jet-stream: Can it? Has it? Will it? Wiley Interdiscip. Rev. Climate Change, 6, 277-286, https:// doi.org/10.1002/wcc.337.

Barton, Y., P. Giannakaki, H. von Waldow, C. Chevalier, S. Pfahl, and O. Martius, 2016: Clustering of regional-scale extreme precipitation events in southern Switzerland. Mon. Wea. Rev., 144, 347-369, https://doi.org/10.1175/MWR-D-15-0205.1.

Bell, G. D., and L. F. Bosart, 1989: A 15-year climatology of Northern Hemisphere $500 \mathrm{mb}$ closed cyclone and anticyclone centers. Mon. Wea. Rev., 117, 2142-2164, https://doi.org/ 10.1175/1520-0493(1989)117<2142:AYCONH>2.0.CO;2.

Bowley, K. A., J. R. Gyakum, and E. H. Atallah, 2019: A new perspective toward cataloging Northern Hemisphere Rossby wave breaking on the dynamic tropopause. Mon. Wea. Rev., 147, 409-431, https://doi.org/10.1175/MWR-D-18-0131.1.

Cohen, J., and Coauthors, 2014: Recent Arctic amplification and extreme mid-latitude weather. Nat. Geosci., 7, 627-637, https://doi.org/10.1038/ngeo2234.

Coumou, D., and S. Rahmstorf, 2012: A decade of weather extremes. Nat. Climate Change, 2, 491-496, https://doi.org/ 10.1038/nclimate1452.

—, V. Petoukhov, S. Rahmstorf, S. Petri, and H. J. Schellnhuber, 2014: Quasi- resonant circulation regimes and hemispheric synchronization of extreme weather in boreal summer. Proc. Natl. Acad. Sci. USA, 111, 12331-12336, https://doi.org/ 10.1073/pnas.1412797111.

_ J. Jehmann, and J. Beckmann, 2015: The weakening summer circulation in the Northern Hemisphere mid-latitudes. Science, 348, 324-327, https://doi.org/10.1126/science.1261768.
Dee, D. P., and Coauthors, 2011: The ERA-Interim reanalysis: Configuration and performance of the data assimilation system. Quart. J. Roy. Meteor. Soc., 137, 553-597, https:// doi.org/10.1002/qj.828.

Doswell, C. A., III, H. E. Brooks, and R. A. Maddox, 1996: Flash flood forecasting: An ingredients-based methodology. Wea. Forecasting, 11, 560-581, https://doi.org/10.1175/ 1520-0434(1996)011<0560:FFFAIB > 2.0.CO;2.

Fischer, E. M., and R. Knutti, 2015: Anthropogenic contribution to global occurrence of heavy-precipitation and hightemperature extremes. Nat. Climate Change, 5, 560-564, https://doi.org/10.1038/nclimate2617.

Francis, J. A., and S. J. Vavrus, 2012: Evidence linking Arctic amplification to extreme weather in mid-latitudes. Geophys. Res. Lett., 39, L06801, https://doi.org/10.1029/2012GL051000.

— and - 2015: Evidence for a wavier jet stream in response to rapid Arctic warming. Environ. Res. Lett., 10, 014005, https://doi.org/10.1088/1748-9326/10/1/014005.

Fritsch, J. M., and R. E. Carbone, 2004: Improving quantitative precipitation forecasts in the warm season: A USWRP research and development strategy. Bull. Amer. Meteor. Soc., 85, 955-965, https://doi.org/10.1175/BAMS-85-7-955.

Gochis, D., and Coauthors, 2015: The Great Colorado Flood of September 2013. Bull. Amer. Meteor. Soc., 96, 1461-1487, https://doi.org/10.1175/BAMS-D-13-00241.1.

Grams, C. M., H. Binder, S. Pfahl, N. Piaget, and H. Wernli, 2014: Atmospheric processes triggering the central European floods in June 2013. Nat. Hazards Earth Syst. Sci., 14, 1691-1702, https://doi.org/10.5194/nhess-14-1691-2014.

Groisman, P. Y., R. W. Knight, and T. R. Karl, 2012: Changes in intense precipitation over the central United States. J. Hydrometeor., 13, 47-66, https://doi.org/10.1175/JHM-D-11-039.1.

Gyakum, J. R., 2008: The application of Fred Sanders' teaching to current research on extreme cold-season precipitation events in the Saint Lawrence River Valley region. Synoptic-Dynamic Meteorology and Weather Analysis and Forecasting: A Tribute to Fred Sanders, Meteor. Monogr., No. 55, 241-250, https:// doi.org/10.1175/0065-9401-33.55.241.

Hoskins, B. J., and T. Woollings, 2015: Persistent extratropical regimes and climate extremes. Curr. Climate Change Rep., 1, 115-124, https://doi.org/10.1007/s40641-015-0020-8.

Kalnay, E., and Coauthors, 1996: The NCEP/NCAR 40-Year Reanalysis Project. Bull. Amer. Meteor. Soc., 77, 437-471, https:// doi.org/10.1175/1520-0477(1996)077<0437:TNYRP>2.0.CO;2.

Koch, S., M. DesJardins, and P. Kocin, 1983: An interactive Barnes objective map analysis scheme for use with satellite and conventional data. J. Climate Appl. Meteor., 22, 1487-1503, https:// doi.org/10.1175/1520-0450(1983)022<1487:AIBOMA>2.0.CO;2.

Kornhuber, K., V. Petoukhov, D. Karoly, S. Petri, S. Rahmstorf, and D. Coumou, 2017: Summertime planetary wave resonance in the Northern and Southern Hemispheres. J. Climate, 30, 6133-6150, https://doi.org/10.1175/JCLI-D-16-0703.1.

Kunkel, K. E., and Coauthors, 2013: Probable maximum precipitation and climate change. Geophys. Res. Lett., 40, 14021408, https://doi.org/10.1002/grl.50334.

Lau, W. K. M., and K.-M. Kim, 2012: The 2010 Pakistan flood and Russian heat wave: Teleconnection of hydrometeorological extremes. J. Hydrometeor., 13, 392-403, https://doi.org/10.1175/ JHM-D-11-016.1.

Lavers, D. A., and G. Villarini, 2013: Were global numerical weather prediction systems capable of forecasting the extreme Colorado rainfall of 9-16 September 2013? Geophys. Res. Lett., 40, 6405-6410, https://doi.org/10.1002/2013GL058282. 
Lejenas, H., and H. Okland, 1983: Characteristics of Northern Hemisphere blocking as determined from a long time series of observational data. Tellus, 35A, 350-362, https://doi.org/ 10.1111/j.1600-0870.1983.tb00210.x.

Lenggenhager, S., S. Bronnimann, and O. Martius, 2019: On the dynamical coupling between atmospheric blocks and heavy precipitation events: A discussion of the southern Alpine flood in October 2000. Quart. J. Roy. Meteor. Soc., 145, 530-545, https://doi.org/10.1002/qj.3449.

Martius, O., C. Schwierz, and H. Davies, 2007: Breaking waves at the tropopause in the wintertime Northern Hemisphere: Climatological analyses of the orientation and the theoretical LC1/2 classification. J. Atmos. Sci., 64, 2576-2592, https:// doi.org/10.1175/JAS3977.1.

_- , and Coauthors, 2013: The role of upper-level dynamics and surface processes for the Pakistan flood of July 2010. Quart. J. Roy. Meteor. Soc., 139, 1780-1797, https://doi.org/ 10.1002/qj.2082.

Milrad, S. M., J. R. Gyakum, and E. H. Atallah, 2015: A meteorological analysis of the 2013 Alberta Flood: Antecedent large-scale flow pattern and synoptic-dynamic characteristics. Mon. Wea. Rev., 143, 2817-2841, https://doi.org/10.1175/ MWR-D-14-00236.1.

_ , K. Lombardo, E. H. Atallah, and J. R. Gyakum, 2017: Numerical simulations of the 2013 Alberta Flood: Dynamics, thermodynamics, and the role of orography. Mon. Wea. Rev., 145, 3049-3072, https://doi.org/10.1175/MWR-D-16-0336.1.

Moore, B. J., K. M. Mahoney, E. M. Sukovich, R. Cifelli, and T. M. Hamill, 2015: Climatology and environmental characteristics of extreme precipitation events in the southeastern United States. Mon. Wea. Rev., 143, 718-471, https://doi.org/10.1175/ MWR-D-14-00065.1.

Munich, R. E., 2017: Natural disasters: The year in figures. Munich RE, accessed 27 August 2018, https://www.munichre.com/ topics-online/en/2017/topics-geo/overview-natural-catastrophe2016.

NCAR, 2018: The NCAR command language, version 6.5.0. UCAR/NCAR/CISL/TDD, Boulder, CO, https://doi.org/ 10.5065/D6WD3XH5.

Overland, J. O., J. F. Francis, R. Hall, E. Hanna, S. Kim, and T. Vihma, 2015: The melting Arctic and midlatitude weather patterns: Are they connected? J. Climate, 28, 7917-7932, https://doi.org/10.1175/JCLI-D-14-00822.1.

Pelly, J. L., and B. J. Hoskins, 2003: A new perspective on blocking. J. Atmos. Sci., 60, 743-760, https://doi.org/10.1175/15200469(2003)060<0743:ANPOB >2.0.CO;2.

Petoukhov, V., S. Rahmstorf, S. Petri, and H. J. Schellnhuber, 2013: Quasiresonant amplification of planetary waves and recent Northern Hemisphere weather extremes. Proc. Natl. Acad. Sci. USA, 110, 5336-5341, https://doi.org/10.1073/pnas.1222000110.

Pfahl, S., and H. Wernli, 2012: Quantifying the relevance of cyclones for precipitation extremes. J. Climate, 25, 6770-6780, https://doi.org/10.1175/JCLI-D-11-00705.1.

— , P. A. O'Gorman, and E. M. Fischer, 2017: Understanding the regional pattern of projected future changes in extreme precipitation. Nat. Climate Change, 7, 423-427, https://doi.org/ 10.1038/nclimate3287.

Philip, S., and Coauthors, 2018: Validation of a rapid attribution of the May/June 2016 flood-inducing precipitation in France to climate change. J. Hydrometeor., 19, 1881-1898, https:// doi.org/10.1175/JHM-D-18-0074.1.

Piaget, N., P. Froidevaux, P. Giannakaki, F. Gierth, O. Martius, M. Riemer, G. Wolf, and C. M. Grams, 2015: Dynamics of a local Alpine flooding event in October 2011: Moisture source and large-scale circulation. Quart. J. Roy. Meteor. Soc., 141, 1922-1937, https://doi.org/10.1002/qj.2496.

Rahmstorf, S., and D. Coumou, 2011: Increase of extreme events in a warming world. Proc. Natl. Acad. Sci. USA, 108, 17905 17909 , https://doi.org/10.1073/pnas.1101766108.

Ralph, F. M., and Coauthors, 2017: Atmospheric rivers emerge as a global science and applications focus. Bull. Amer. Meteor. Soc., 98, 1969-1973, https://doi.org/10.1175/BAMS-D-16-0262.1.

Rex, D. F., 1950: Blocking action in the middle troposphere and its effect upon regional climate. Part I: An aerological study of blocking action. Tellus, 2, 196-211, https://doi.org/10.1111/ j.2153-3490.1950.tb00331.x.

Roberge, A., J. R. Gyakum, and E. H. Atallah, 2009: Analysis of intense poleward water vapor transports into high latitudes of western North America. Wea. Forecasting, 24, 1732-1747, https://doi.org/10.1175/2009WAF2222198.1.

Schamm, K., M. Ziese, K. Raykova, A. Becker, P. Finger, A. Meyer-Christoffer, and U. Schneider, 2015: GPCC full data daily version 1.0 at $1.0^{\circ}$ : Daily land-surface precipitation from rain-gauges built on GTS-based and historic data. Deutscher Wetterdienst, accessed 15 June 2018, https:// doi.org/10.5676/DWD_GPCC/FD_D_V1_100.

Screen, J. A., and I. Simmonds, 2014: Amplified mid-latitude planetary waves favour particular regional weather extremes. Nat. Climate Change, 4, 704-709, https://doi.org/10.1038/nclimate2271.

Sisson, P. A., and J. R. Gyakum, 2004: Synoptic-scale precursors to significant cold-season precipitation events in Burlington, Vermont. Wea. Forecasting, 19, 841-854, https://doi.org/ 10.1175/1520-0434(2004)019<0841:SPTSCP > 2.0.CO;2.

Stucki, P., R. Rickli, S. Brönnimann, O. Martius, H. Wanner, D. Grebner, and J. Luterbacher, 2012: Weather patterns and hydro-climatological precursors of extreme floods in Switzerland since 1868. Meteor. Z., 21, 531-550, https:// doi.org/10.1127/0941-2948/2012/368.

Sukovich, E. M., F. M. Ralph, F. E. Barthold, D. W. Reynolds, and D. R. Novak, 2014: Extreme quantitative precipitation forecast performance at the Weather Prediction Center from 2001 to 2011. Wea. Forecasting, 29, 894-911, https://doi.org/10.1175/ WAF-D-13-00061.1.

Teufel, B., and Coauthors, 2017: Investigation of the 2013 Alberta Flood from weather and climate perspectives. Climate Dyn., 48, 2881-2899, https://doi.org/10.1007/s00382-016-3239-8.

Tibaldi, S., and F. Molteni, 1990: On the operational predictability of blocking. Tellus, 42A, 343-365, https://doi.org/10.3402/ tellusa.v42i3.11882.

Wang, S.-Y. S., L. Zhao, and R. R. Gillies, 2016: Synoptic and quantitative attributions of the extreme precipitation leading to the August 2016 Louisiana flood. Geophys. Res. Lett., $\mathbf{4 3}$, 11 805-11 814, https://doi.org/10.1002/2016GL071460.

Yamada, T. J., D. Takeuchi, M. A. Farukh, and Y. Kitano, 2016: Climatological characteristics of heavy rainfall in Northern Pakistan and atmospheric blocking over western Russia. J. Climate, 29, 7743-7754, https://doi.org/10.1175/JCLI-D-150445.1. 